المجلة الدولية للدراسات التربوية والنفسية e-ISSN 2520-4149 , p-ISSN 2520-4130

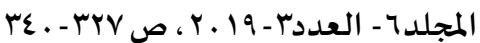

رفاد للدراسات والأبحاث www.refaad.com

.

\title{
متطلبات الحوكمة الرشيدة في مدارس التعليم العام للبنات بمحافظة ينبع من وجهة نظر

$$
\text { مديرات المدارس }
$$

\section{مجدلين محمود القاعود}

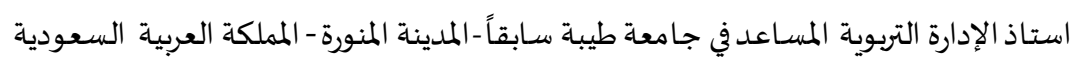

Magiq100@gmail.com

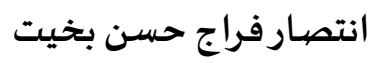 \\ إدارة التعليم العام بينبع - المملكة العربية السعودية جسية \\ entbkt13@gmail.com
}

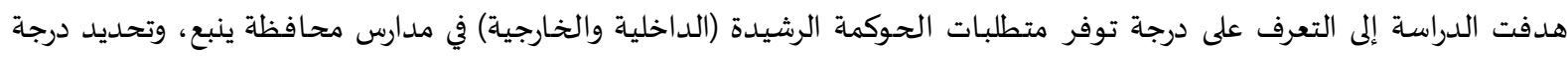

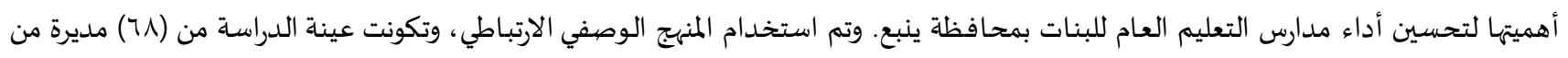

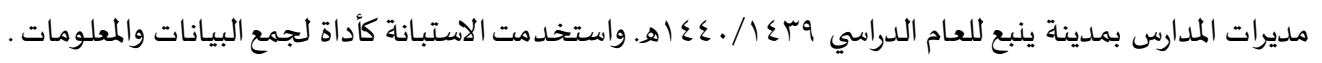

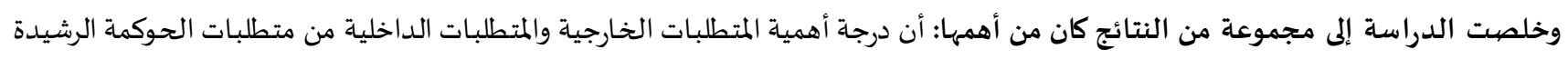

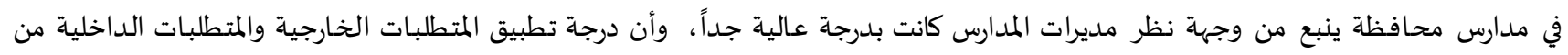

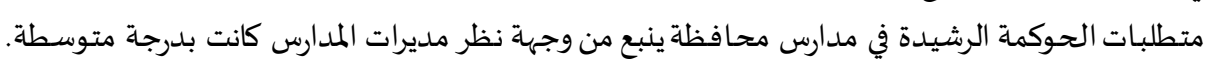

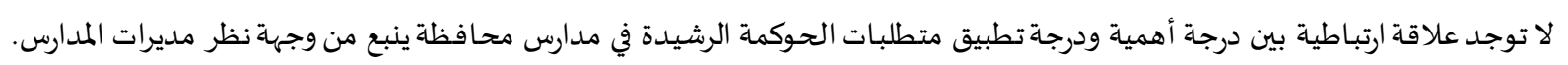

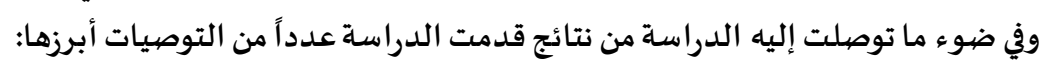

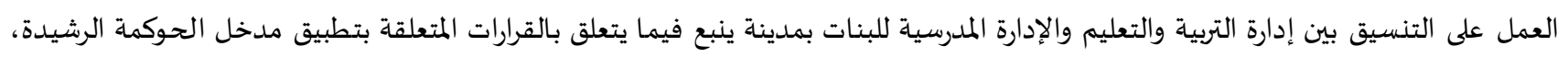

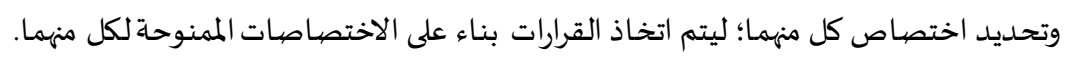

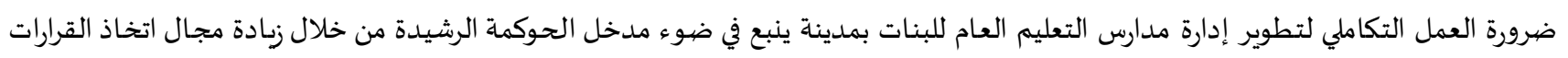

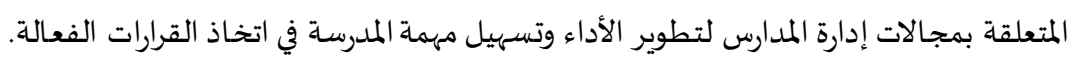

الكلمات المفتاحية: الحوكمة الرشيدة؛ متطلبات الحوكمة؛ مدارس التعليم العام للبنات؛ بينبع (ब) (1)

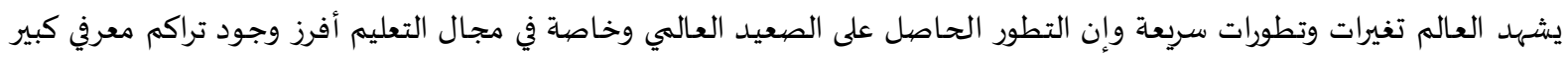

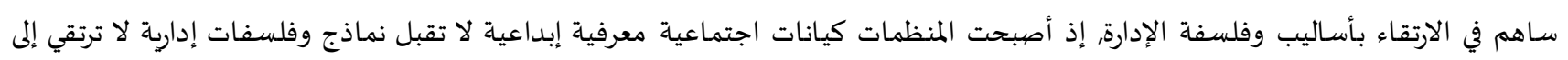

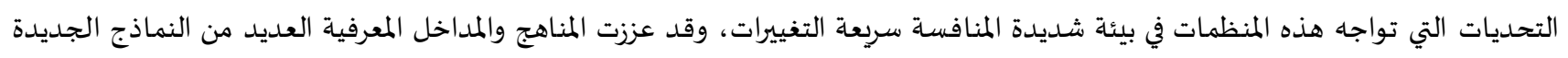

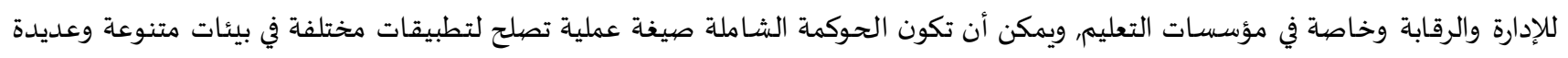

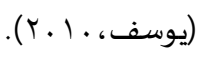

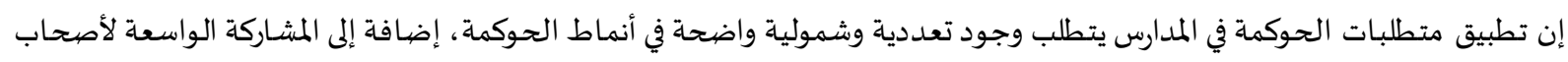

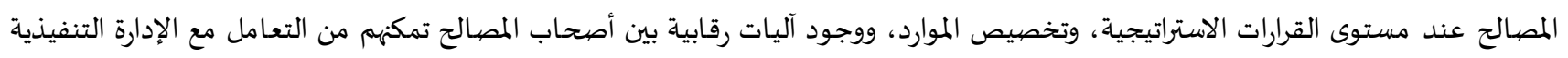


وتوجياء سلوكهم, هذا من جانب، ومن جانب آخر لا بد من وجود رقابة داخلية مشكّلة من مجلس الحوكمة وتقدم تقريرها عن مدى الالتزام بالأنظمة

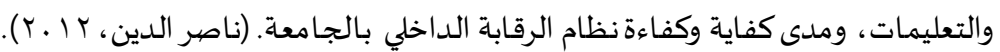
وتواجه عملية تطبيق الحوكمة الجيدة في التعليم عدد من المعوقات أشارت لها العديد من الدراسات في جوانب ومجالات مختلفة، فقد حدد (

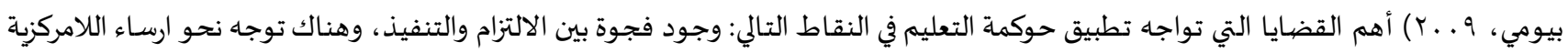
في مجال تنفيذ الأنشطة الخاصة بالتعليم المجتمعي، ودعم برامج التأهيل والتدربب لبناء القدرات الوطنية في مجال التعليم المجتمعي.

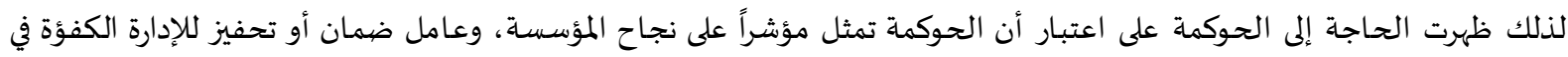

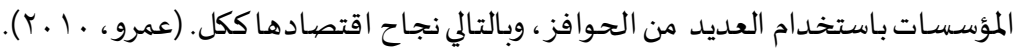

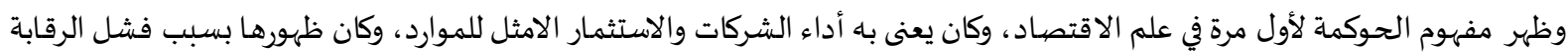

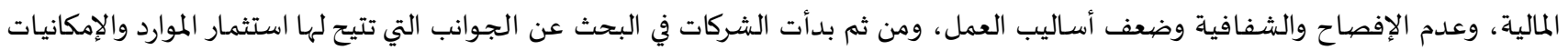
وتوظيفها في الجوانب التنظيمية والإدارية. (أبو بكر، 0. . . ب).

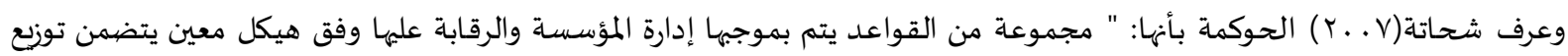

الحقوق والواجبات بين المشاركين في إدارة المؤسسـة".

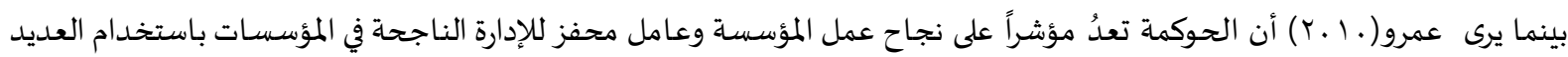
من العمليات التي تعمل عل تقوية عمل المؤسسة على المدى البعيد وتحديد المسئول والمسؤولية.

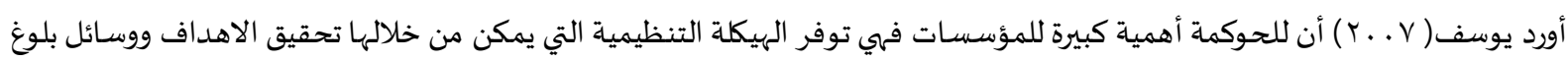

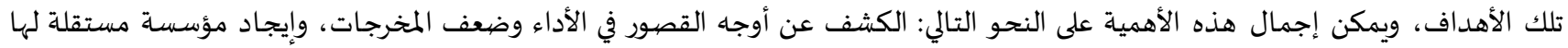

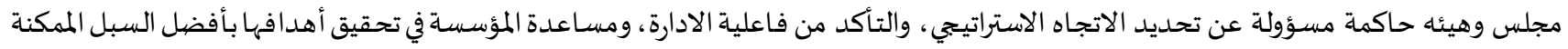
ومن ثم تعزيز القدرة التنافسية وتجنب العناء الإداري والمادي. ومما سبق ترى الباحثتان أن الحوكمة إذا ما طبقت في المؤسسات التعليمة، فإنها يمكن أن تمكن من رفع كفاءة المدرسة، ووضع الإطار

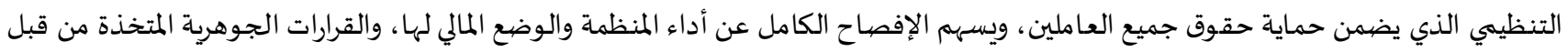
الإدارة؛ مما ينعكس على زيادة ثقة المجتمع في المدرسة

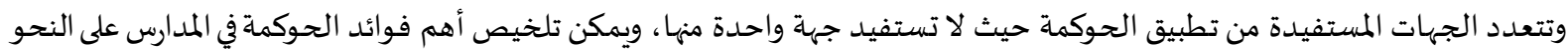

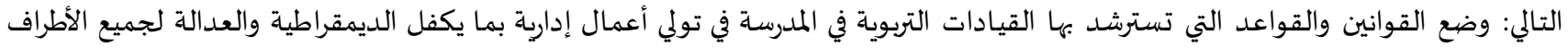

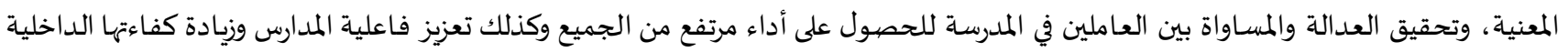
والخارجة من خلال تكوين بيئة صالحة للعمل، وتوفير حق المساءلة لجميع الأطراف المستفيدة من وجود الحوكمة في المدرسة، وتحقيق مشاركة جميع

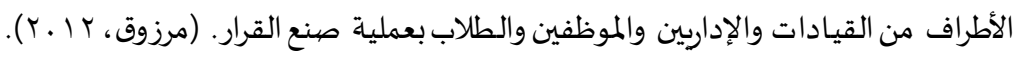

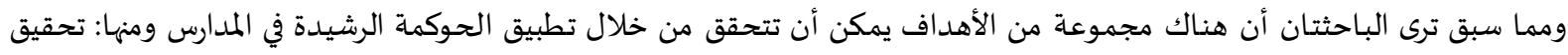

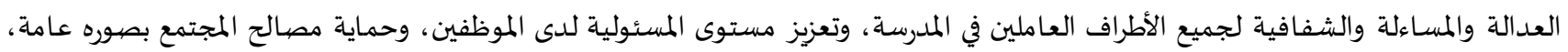

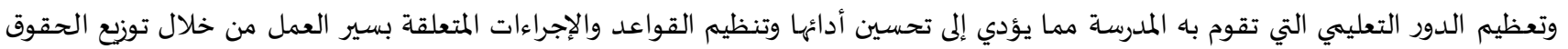
والمسئوليات بين الإدارة والعاملين.

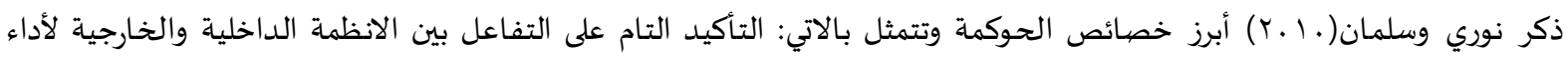

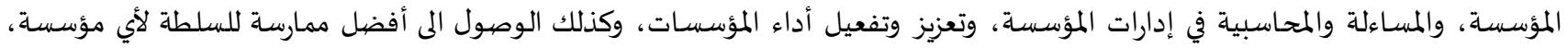

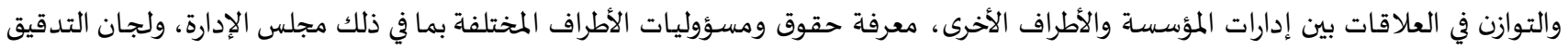
والمراقبة ، وأصحاب المصالح المختلفة.

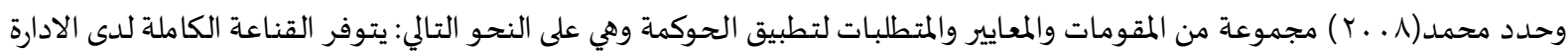
المدرسية بقبول مبادئ الحوكمة وقواعدها، ووضوح التشريعات والسياسات والقواعد الحاكمة التي تسهل عملية التطبيق، وكذلك وضيوح إمكانية

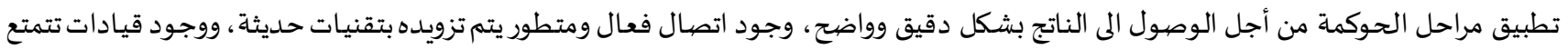
بالكفاءة والخبرة والمؤهلات المناسبة.

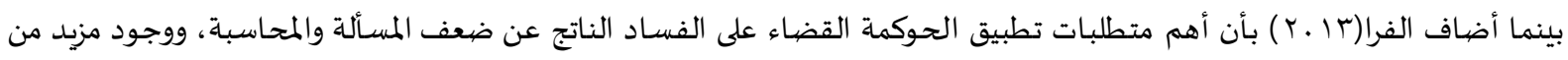

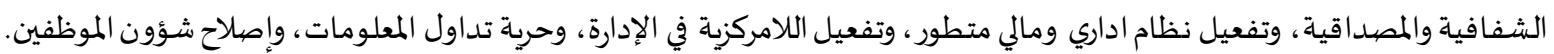

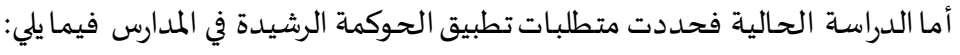


المتطلبات الخارجية: وتتمثل في قناعة المسؤولين بجدوى الحوكمة كأداة لجودة الإنتاج، اعتماد مبادئ الحوكمة كأحد عناصر تحسين الأداء المدرسي، إشراك لجان تدقيق ومراجعة من خارج المدرسة لمراجعة أدائها المالي والإداري، الإفصاح عن مؤشر الأداء للإدارة التنفيذية بشكل

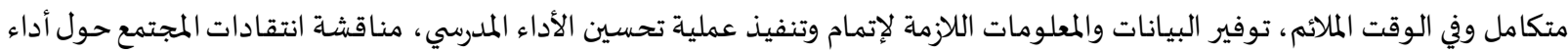

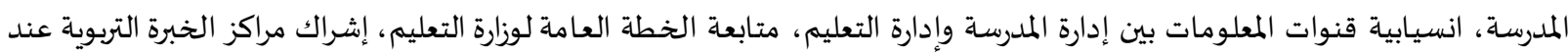

وضيع الخطة الاستراتيجية للمدرسة.

المتطلبات الداخلية: وتتمثل في القدرة على تحليل المشكلات المدرسية، القدرة على اتخاذ القرار الرشيد، إلحاق الإداريات والمعلمات داخل

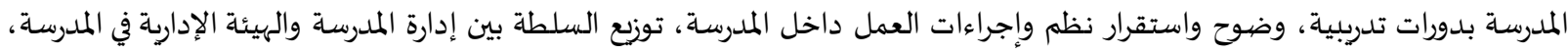
تشجيع المعلمات في تقديم مقترحات خاصة بأدائهن داخل المدرسة، وجود أسس عادلة في نظام الحوافز للعاملين في المدرسة، الالتزام

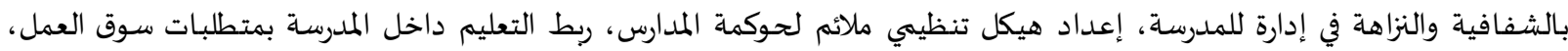

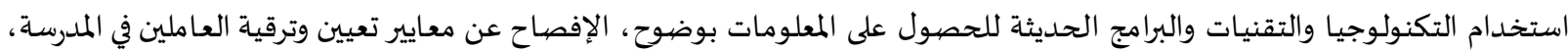

تحقيق استقلالية المدرسة في جميع مجالات عملها.

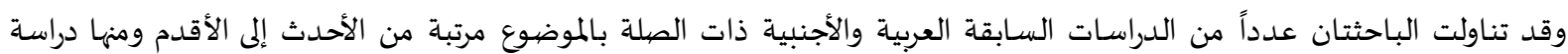

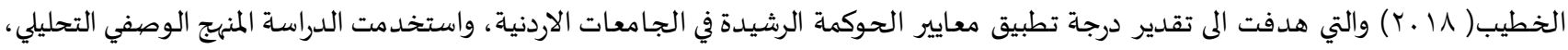

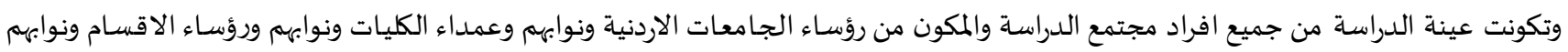

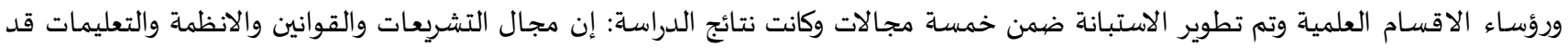

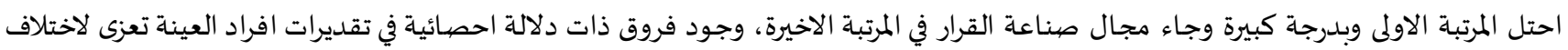
متغير الجامعة وذلك لصالح الجامعات الحكومية كما تبين وجود فروق ذات دالة احصائياً تعزى لمتغير الموقع الاكاديمي وذلك لصالح دهالح متغيرات ذوي

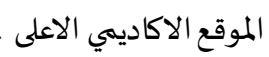

وهدفت دراسة قرواني(7 ا ـ ا ) الى الكشف عن مدى ممارسة الحوكمة في المدارس الثانوية في فلسطين من وجهاة نظر المعلمين والمعلمات فهها، وكانت الاستبانة أداة الدراسة واستخدم المنهج الوصفي التحليلي، وتوصلت الدراسة إلى نتائج أهمها: وجود ممارسة للحوكمة في المدارس الثانوية في

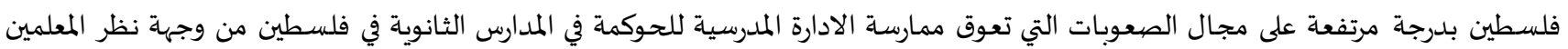

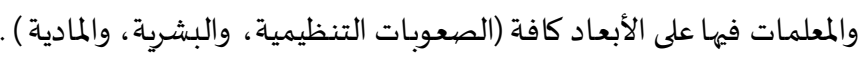
أما دراسة المفيز ( VI乏 ا ) فهدفت الى التعرف على واقع تطبيق الحوكمة في الجامعات السعودية الحكومية والمعوقات التي تحول دون

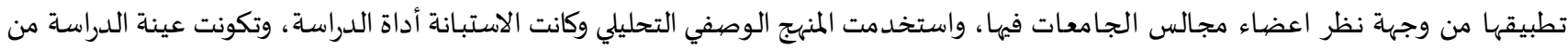

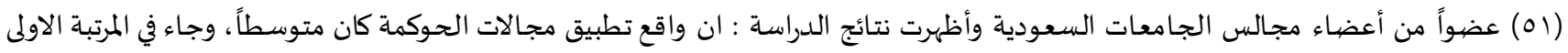
مجال السلطة والادارة ومجال المشاركة في المرتبة الاخيرة

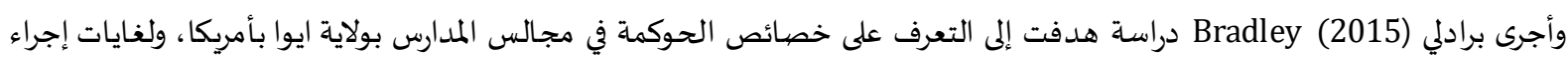
الدراسة تم استطلاع وجهات نظر أعضاء مجلس إدارة المدارس بالولاية لعرض خصائص الحكم الفعال واستخدمت الدراسة المنهج النوعي، وكانت اداة

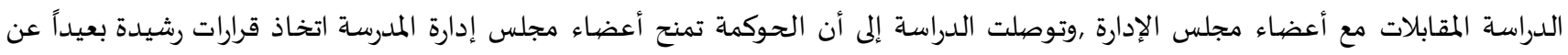

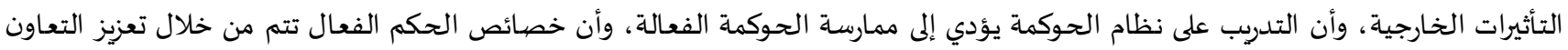

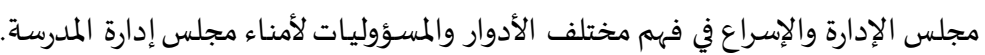
وهدفت دراسة جنيفر وديام (2015) Jennifer \& Diem إلى التعرف على أثر الحوكمة في إصلاح الإدارة المدرسية في التعليم العام التي

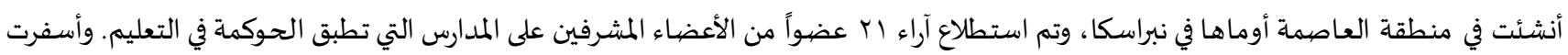

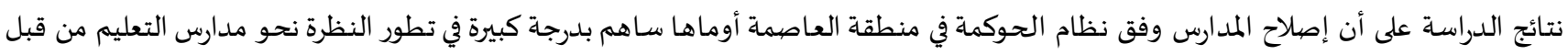

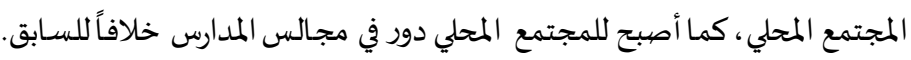

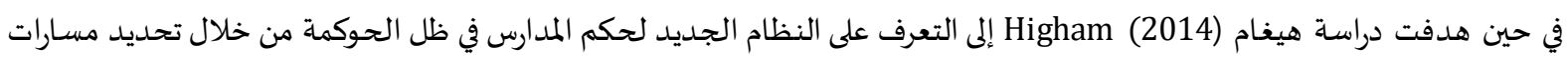

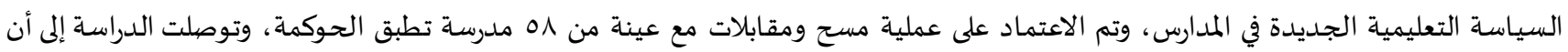

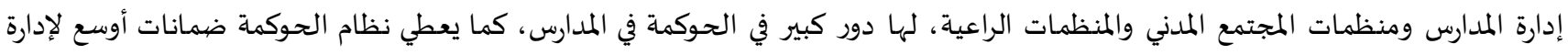
المدارس، وهذا يساعد على تحسين عملية التعليم وتحسين مستوى الأداء المدرسي .

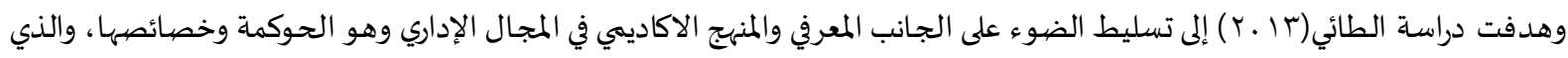

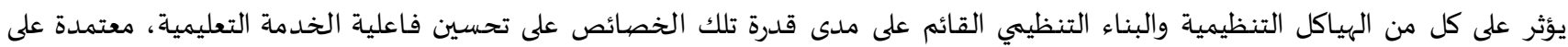




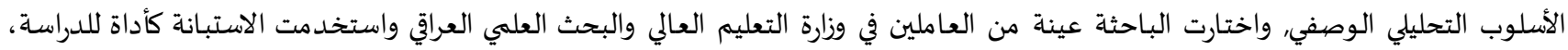

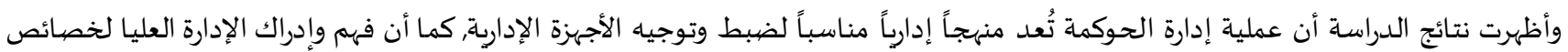
الحكمانية يسهم في تعزيز وتحقيق مستويات أداء عالية الجودة.

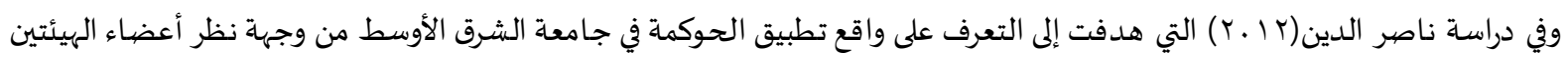

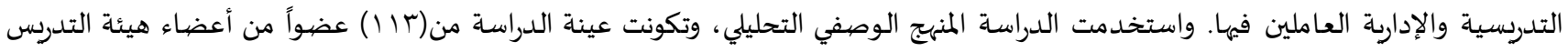

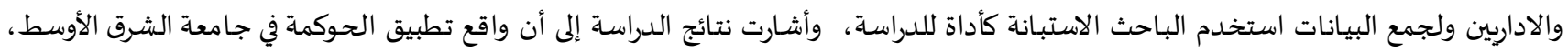

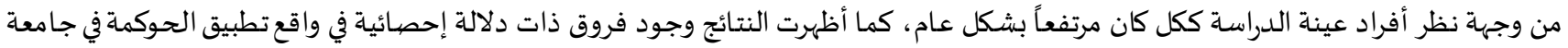
الشرق الأوسط تبعاً لاختلاف المركز الوظيفي، وعدد سنوات المرات الخبرة.

التعليق على الدراسات السابقة : البات

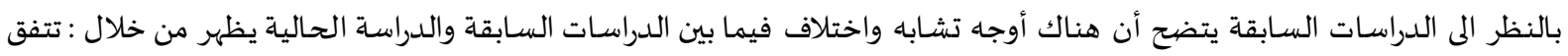

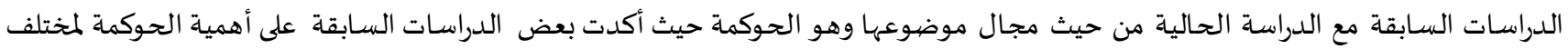

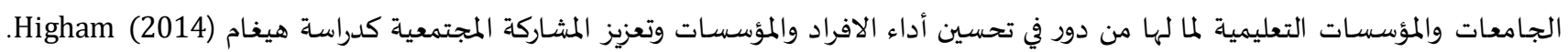

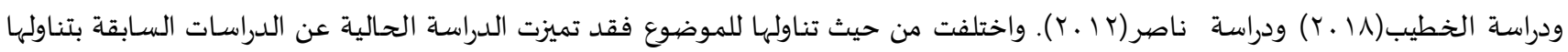

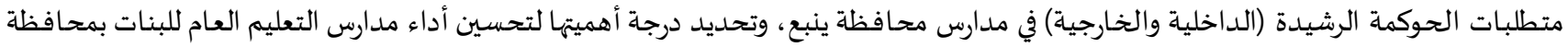

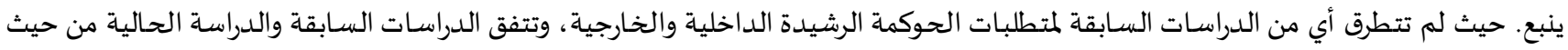

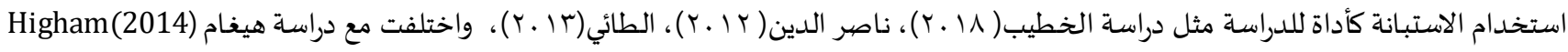

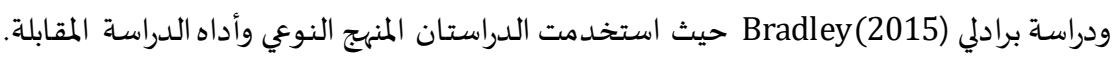

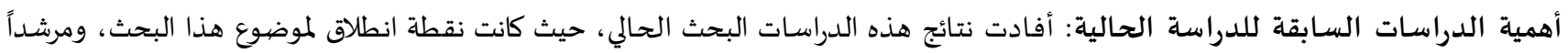

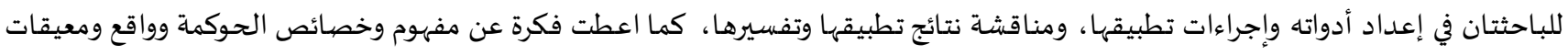
تطبيق الحوكمة في الجامعات والمؤسسات فئنات أدواته

مشكلة الدراسـة وأسئلتها:

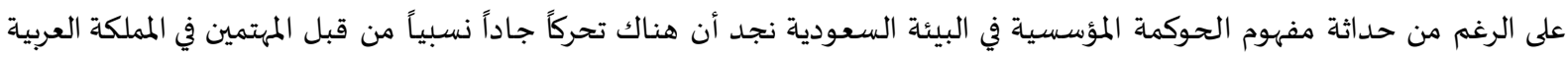

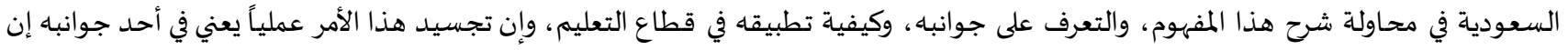

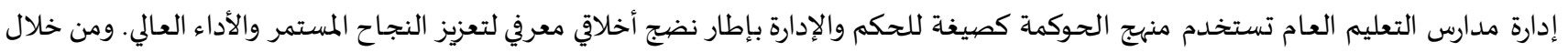

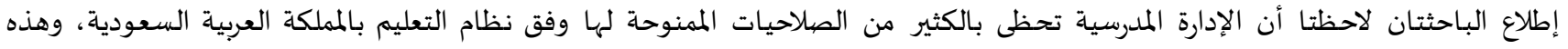

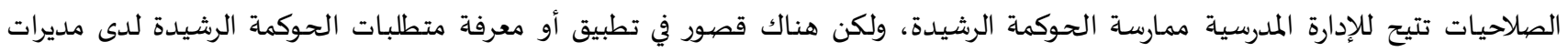

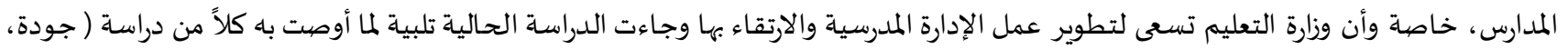

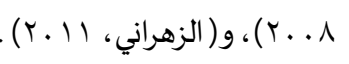
وتنبع أسئلة الدراسة الحالية من السؤال الرئيسي الآتي:

ما متطلبات الحوكمة الرشيدة في مدارس التعليم التيم العام للبنات بمحافظة ينبع من وجهة نظرمديرات المدارس؟

وتتفرع منه الأسئلة التالية:

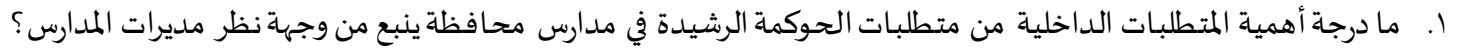

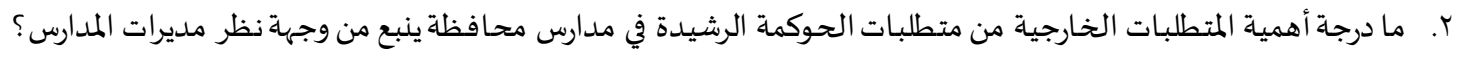

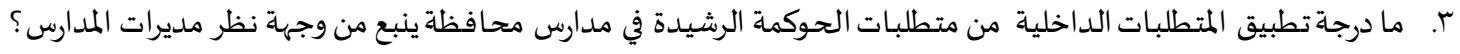

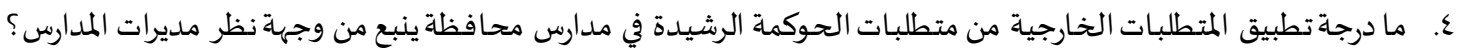

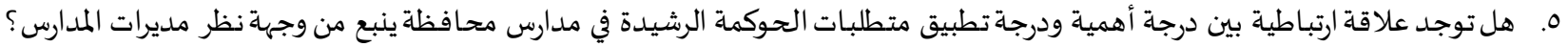




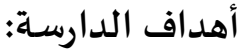

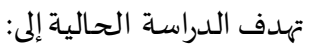

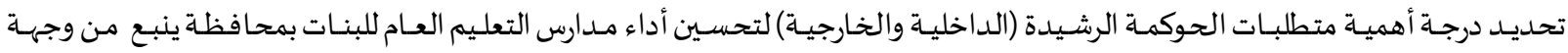

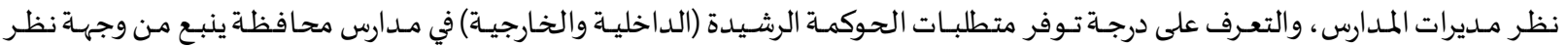
مديرات المدارس. التعرف على العلاقة الارتباطية بين واقع أهمية وتطبيق متطلبات الحوكمة الرشيدة في مدارس محافظة ينبع من وجهة نظر مديرات المدارس.

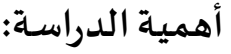

تتمثل أهمية الدراسة الحالية فيما يلي: • تقديم طحح فكري عن إمكانية تطبيق متطلبات الحوكمة الرشيدة في مدارس التعليم العام بمحافظة ينبع في عصر المعرفة، ودرجة أهميتها

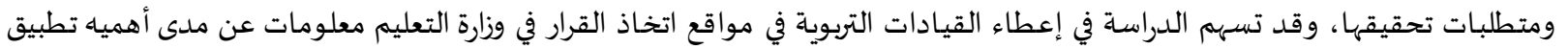

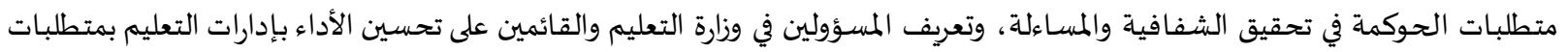

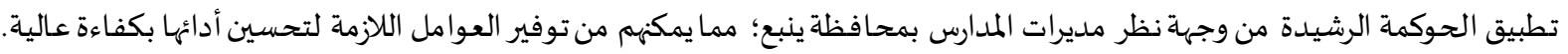

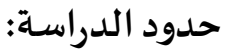
أولاً: الحدود الموضوعية: معرفة درجة أهمية ودرجة تطبيق مديرات المدارس في محافظة ينبع لمتطلبات الحوكمة الرشيدة المتمثلة في: (المتطلبات

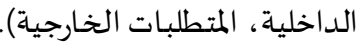

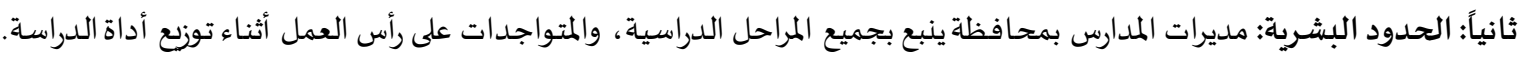

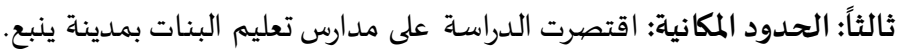

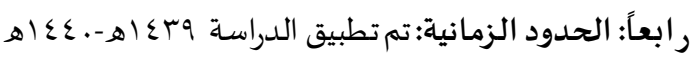

\section{مصطلحات الدراسـة:}

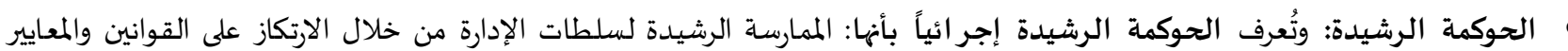

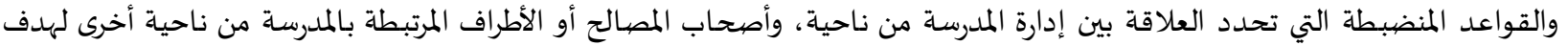

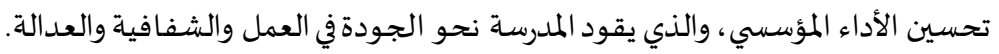

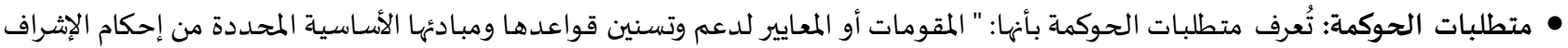

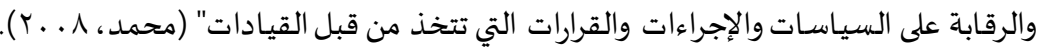

\section{منهجية الدراسـة وإجراءاتها} أولاً: منهج الدراسة: استخدمت الدراسة المنهج الوصفي الارتباطي، الذي يحاول من خلالكه رصد واقع تطبيق متطلبات الحوكمة الرشيدة في مدارس

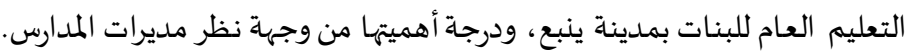

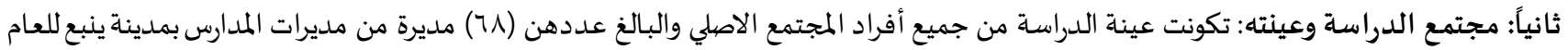

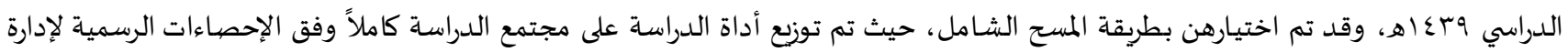

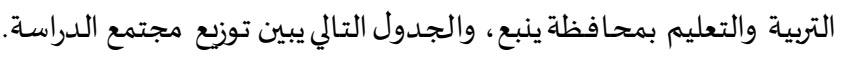

\begin{tabular}{|c|c|c|}
\hline النسبة & العدد & المرحلة الدراسية \\
\hline$\% 00,9$ & rᄉ & ابتدائي \\
\hline$\% r V, q$ & 19 & متوسط \\
\hline$\% 17, r$ & 11 & ثانوي \\
\hline$\% 1 .$. & 71 & المجموع \\
\hline
\end{tabular}


ثالثًا: أداة الدراسة: لتحقيق هدف الدراسة اعتمدت الباحثتان على الاستبانة كأداة لجمع البيانات والمعلومات ولصياغة فقرات الاستبانة تم مراجعة الأدب النظري المرتبط بواقع وأهمية تطبيق متطلبات الحوكمة الرشيدة في مؤسسات التعليم من وجهة نظر القادة التربويين، ومراجعة مقاييس الدراسـات السـابقة التي استخدمت للتعرف على واقع وأهمية تطبيق متطلبات الحوكمة الرشيدة في مؤسسات التعليم، والمصادر السابقة ، والموضوعات المشتملة علهيها، من أجل تحديد

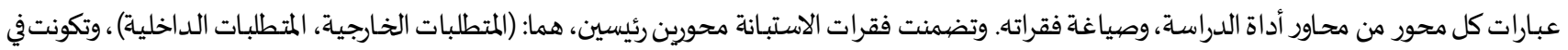

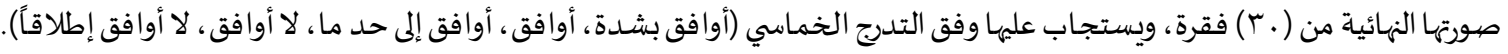

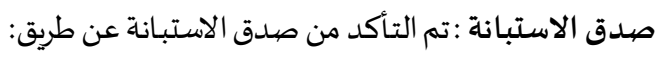
أ • صددق المحكمين: تم عرض الاستبانة على مجموعاة من المحكمين من ذوي الاختصاص في في التربية ، للاسترشاد بآرائهم في مدى مناسبة فقرات الاست الاستبانة للهدف منها،

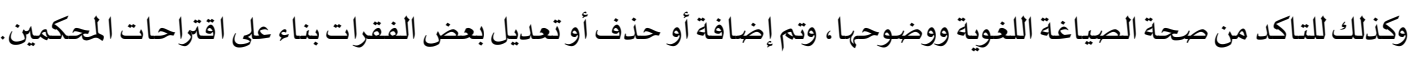

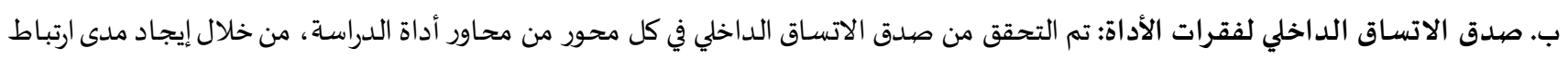

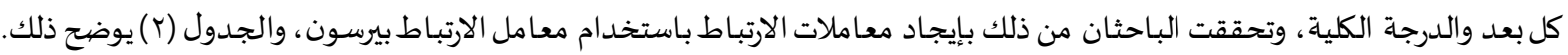

جدول(r) : الاتسـاق الداخلي لأداة الدراسة ومحاورها

\begin{tabular}{|c|c|}
\hline معامل الارتباط & محاور أداة الدراسة \\
\hline **.,V乏r & المتطلبات الخارجية \\
\hline$* *, \vee \vee \wedge 9$ & المتطلبات الداخلية \\
\hline
\end{tabular}

* * توجد دلالة إحصبائية عند مستوى (1. . .).

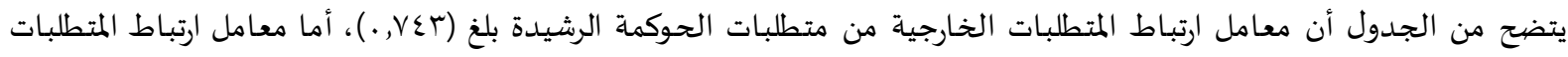

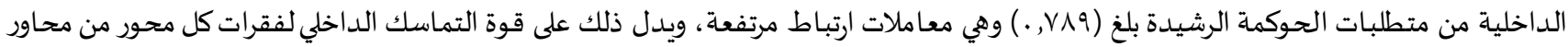
أداة الدراساة. ثبات أداة الدراسـة: تمَّ استخراج معامل ثبات أداة الدراسة بطريقة الفا كرونباخ، وقد بلغ الثبات الكلي (؟ ـ 9, .)، وهو معامل ثبات مرتفع ومناسب

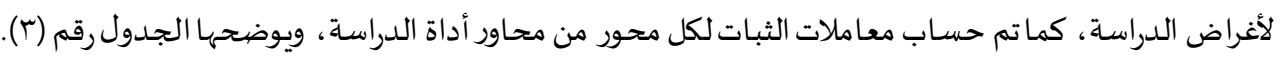
جدول(ץ): معاملات الثبات لمحاورأداة الدراسـة

\begin{tabular}{|c|c|}
\hline الفا كرونباخ & محاور أداة الدراسـة \\
\hline$\cdot, \wedge \wedge \varepsilon$ & المتطلبات الخارجية \\
\hline .,9Y1 & المتطلبات الداخلية \\
\hline$\cdot, q . r$ & الثبات الكلي \\
\hline
\end{tabular}

رابعاً: الأسـاليب والمعالجات الإحصائية:وتمثلت فيما يلي: معامل الارتباط بيرسون لحساب صـدق الاتساق الداخلي، ومعامل ثبات أداة الدراسة بطريقة الفا كرونباخ، وكذلك المتوسطات الحسابية والانحرافات المعيارية للتعرف على درجة أهمية ودرجة تطبيق متطلبات الحوكمة الرشيدة (الداخلية والخارجية) لتحسين أداء مدارس التعليم

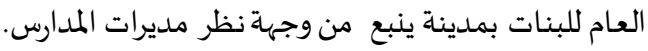

\section{نتائج الدراسـة وتفسيرها ومناقشتها • إجابة السؤال الأول وتفسيره ومناقشته:}

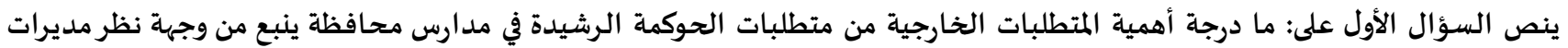
المدارس؟ ولإجابة عن هذا السؤال تمَّ استخراج المتوسطات الحسابية والانحرافات المعيارية لجميع العبارات التي تمثل درجة أهمية المتطلبات الخارجية من متطلبات الحوكمة الرشيدة في مدارس محافظة ينبع. 
جدول(ع): المتوسّطات الحسابية والانحر افات المعيارية لدرجة تطبيق المتطلبات الخارجية من متطلبات الحوكمة الرشيدة في مدارس محافظة ينبع من وجهة نظر مديرات المدارس

\begin{tabular}{|c|c|c|c|c|c|}
\hline التقدير & المعياري & المستوسط & ترتيب العبارة تنازلياً حسب المتوسطات & المقبارة في & 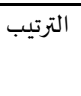 \\
\hline درجة عالية جداً & . VTY & $\varepsilon$, or & يتم دفع مخصصيات المدرسة بناء على احتياجاتها الفعلية & $\Lambda$ & 1 \\
\hline 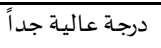 & . V V & $\varepsilon, \varepsilon 9$ & أقوم باستثمار مرافق المدرسة للحصول على تمويل إضافي & 9 & r \\
\hline درجة عالية جداً & $\cdot, V \varepsilon r$ & $\varepsilon, \varepsilon 7$ & اقنع المسؤولين بجدوى الحوكمة كأداة لجودة الإنتاج & 1 & $r$ \\
\hline 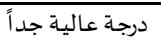 &., 9.4 & $\varepsilon, \varepsilon r$ & احرص على تدريب وتأهيل العاملات خارجياً & 1. & $\varepsilon$ \\
\hline درجة عالية جداً & $\cdot, 101$ & $\varepsilon, \varepsilon 1$ & أشرك لجان تدقيق ومراجعة من خارج المدرسة لمراجعة أدائها المالي والإداري & r & o \\
\hline درجة عالية جداً & .,Vre & $\varepsilon, \varepsilon$. & أفصح عن مؤشر الأداء للإدارة التنفيذية بشكل متكامل وفي الوقت الملائم & $\varepsilon$ & 1 \\
\hline درجة عالية جداً & $\cdot$, A & $\varepsilon, r v$ & اعتمد مبادئ الحوكمة كأحد عناصر تحسين الأداء المدرسيي & r & $\mathrm{v}$ \\
\hline 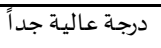 & $\cdot, \mathrm{AVV}$ & $\varepsilon, r_{0}$ & أوفر البيانات والمعلومات اللازمة لإتمام وتنفيذ عملية تحسين الأداء المدرسي & o & $\wedge$ \\
\hline درجة عالية جداً & $\cdot, 199$ & $\varepsilon, \Upsilon^{9}$ & ارحب بمناقشة انتقادات المجتمع حول على أداء المدرسة & 7 & 9 \\
\hline درجة عالية & $\cdot, 9 \uparrow 7$ & $\varepsilon, .9$ & اتابع الخطة العامة لوزارة التعليم & 11 & 1. \\
\hline درجة عالية & $\cdot, 9 \leq \varepsilon$ & $\varepsilon, \cdot V$ & أشرك مراكز الخبرة التربوية عند وضع الخطة الاستراتيجية للمدرسة & ir & 11 \\
\hline 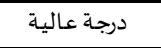 & $\cdot, 994$ & $\varepsilon, .$. & اعمل على انسيابية قنوات المعلومات بين إدارة المدرسة وإدارة التعليم & $\mathrm{v}$ & it \\
\hline درجة عالية جداً & . , $\leqslant \varepsilon V$ & $\varepsilon, r_{Y}$ & المتوسط الحسابي & & \\
\hline
\end{tabular}

يتبين من الجدول السابق أن درجة أهمية المتطلبات الخارجية من متطلبات الحوكمة الرشيدة في مدارس محافظة ينبع من وجهة نظر مديرات

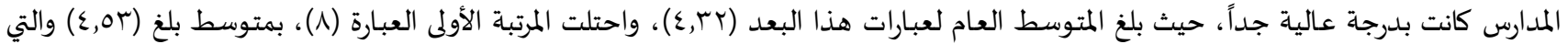
تنص على: "يتم دفع مخصصيات المدرسة بناء على احتياجاتها الفعلية". وقد تُعزى هذه النتيجة إلى أن جميع مديرات المدارس بمدينة ينبع يدركن أهمية

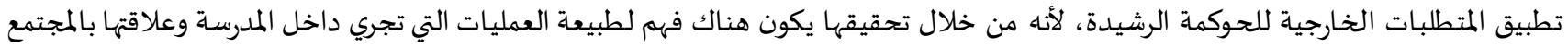

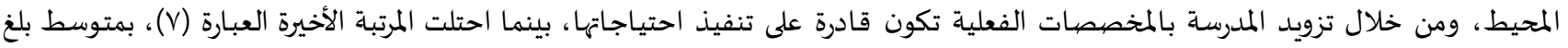

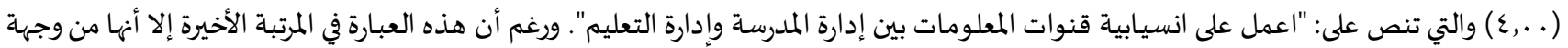
نظر الباحثتان مهمة بدرجة عالية، حيث إن توفر قنوات المعلومات يؤدي إلى كفاءة وفعالية الحوكمة الرشيدة من خلال مشـاركة جميع الأطراف في

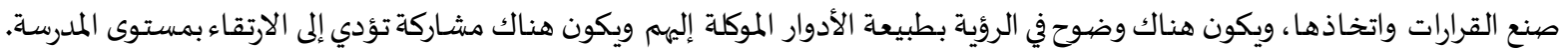
• •

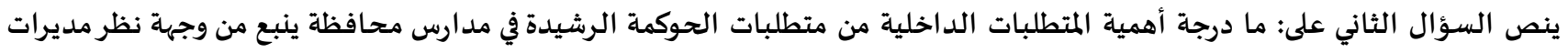
المدارس؟ ولإجابة عن هذا السؤال تمَّ استخراج المتوسطات الحسابية والانحرافات المعيارية لجميع العبارات التي تمثل درجة أهمية المتطلبات الداخلية من متطلبات الحوكمة الرشيدة في مدارس محافظة ينبع من وجهاة نظر مديرات المدارس.

جدول(0): المتوسّطات الحسابية والانحر افات المعيارية لدرجة تطبيق المتطلبات الداخلية من متطلبات الحوكمة الرشيدة في مدارس محافظة ينبع من وجهة نظر مديرات المدارس

\begin{tabular}{|c|c|c|c|c|c|}
\hline التقدير & 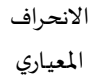 & الحسابي - المتوسط & ترتيب العبارة تنازلياً حسب المتوسطات & العبارة في المقياس & الترتيب \\
\hline درجة عالية جداً &., 0 r7 & $\varepsilon, 77$ & أقوم بإعد اد هيكل تنظيهي ملائم لحوكمة المدارس & ri & 1 \\
\hline درجة عالية جداً & · & $\varepsilon, 7 \pi$ & أوزع السلطة بين إدارة الممدرسة والهيئة الإدارية في المدرسة & IV & r \\
\hline درجة عالية جداً & ש & $\varepsilon, 7 \pi$ & أوجد أسس عادلة في نظام الحوافز للعاملين في المدرسة & 19 & r \\
\hline درجة عالية جداً & -,VET & $\varepsilon, 0 \varepsilon$ & بوضوح & r & $\varepsilon$ \\
\hline درجة عالية جداً & ., V.Y & $\varepsilon, 01$ & التزم بالشفافية والنزاهة في إدارتي للمدرسة & r. & 0 \\
\hline درجة عالية جداً & . VTr & $\varepsilon, 0$. & استغل المواردوالإمكانيات المتاحة في المدرسة بشكل ملائم & TV & 7 \\
\hline درجة عالية جداً & $\cdot, \mathrm{r}$. & $\varepsilon, \varepsilon \wedge$ & احقق استقلالية المدرسة في جميع مجالات عملها & r & $\mathrm{v}$ \\
\hline درجة عالية جداً & -, $\mathrm{9} 9$ & $\varepsilon, \varepsilon \varepsilon$ & كفاءتهن وفعالية أد ائهن الإداريات والمعلم مات دا خل المدرسة بدورات تدريبية لرفع & 10 & $\wedge$ \\
\hline درجة عالية جداً & . & $\varepsilon, \varepsilon r$ & أفصح عن معايير تعيين وترقية العاملين في المدرسة & ro & 9 \\
\hline درجة عالية جداً & ., vor & $\varepsilon, r q$ & سير العمل بتوفير قنوات اتصال فعالة مع أفراد المدرسة للحصول على معلومات عن & rq & 1. \\
\hline
\end{tabular}




\begin{tabular}{|c|c|c|c|c|c|}
\hline درجـة عالية جداً & 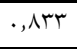 & $\varepsilon$, ґᄉ & احرص على وضع بدائل في الخطة الاستراتيجية & $r$. & 11 \\
\hline درجة عالية جداً & $\cdot, \wedge \varepsilon$. & $\varepsilon, r \varepsilon$ & لدي معرفة بمتطلبات الحوكمة وأهد افها في تحقيق جودة الأداء المدرسي & ru & IT \\
\hline درجة عالية جداً & $\cdot, \mathrm{V} \vee \mathrm{A}$ & $\varepsilon, r$ & اتمتع بالقدرة على تحليل المشكلات المدرسية & ir & Ir \\
\hline درجة عالية جداً & $\cdot, \wedge 71$ & $\varepsilon, \uparrow \wedge$ & اعمل على وضوح واستقرار نظم وإجراءات العمل داخل المدرسـة & 17 & $1 \varepsilon$ \\
\hline درجة عالية جداً & $\cdot, 9 \leq \varepsilon$ & $\varepsilon, T V$ & احقق مستوى من الثقة بين إدارة المدرسة والعاملين فها & $r \varepsilon$ & 10 \\
\hline درجة عالية جداً &., 99 & $\varepsilon, Y r$ & ربط التعليم داخل المدرسة بمتطلبات سوق العمل & rr & 17 \\
\hline درجة عالية & $\cdot, 9 \varepsilon$. & $\varepsilon, 17$ & امتلك القدرة على اتخاذ القرار الرشيد & $1 \varepsilon$ & IV \\
\hline 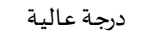 & $1, .7 r$ & $\varepsilon, .7$ & اشجع المعلمات في تقديم مقترحات خاصية بأدائهن داخل المدرسة & 11 & 11 \\
\hline درجة عالية جداً & $\cdot, \mathrm{Vqr}$ & $\varepsilon, \varepsilon$. & المتوسط الحسابي & & \\
\hline
\end{tabular}

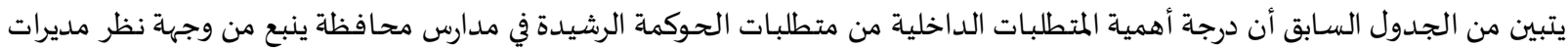

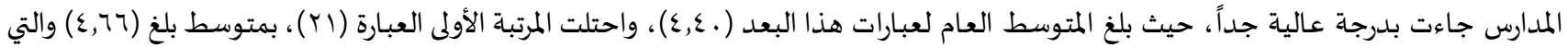

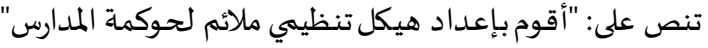

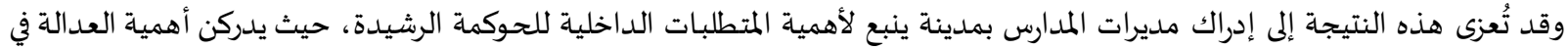

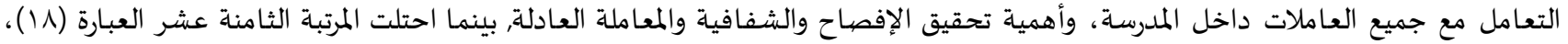

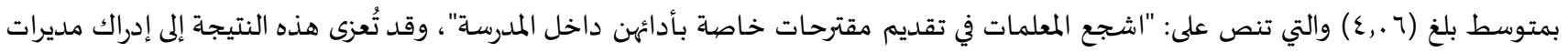

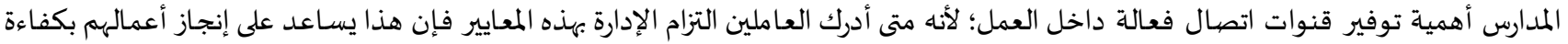

ودافعية أكبر.

• إجابة السؤال الثالث وتفسيره ومناقشته: ينص السؤال الثالث على: ما درجة تطبيق المتطلبات الخارجية من متطلبات الحوكمة الرشيدة في مدارس محافظة ينبع من وجهة نظر مديرات المدارس؟ ولالإبابة عن هذا السؤال تمَّ استخراج المتوسطات الحسابية والانحرافات المعيارية لجميع العبارات التي تمثل درجة تطبيق المتطلبات الخارجية من متطلبات الحوكمة الرشيدة في مدارس محافظة ينبع من وجها نظر مديرات المدارس.

جدول(7): المتوسّطات الحسابية والانحر افات المعيارية لدرجة تطبيق المتطلبات الخارجية من متطلبات الحوكمة الرشيدة في مدارس محافظة ينبع من وجهة

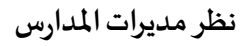

\begin{tabular}{|c|c|c|c|c|c|}
\hline 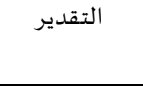 & الالنحراف & المستوسط المبي & ترتيب العبارة تنازلياً حسب المتوسطات & العبارة في & الترتيب \\
\hline درجة عالية & $\cdot, \wedge 10$ & $\varepsilon, 10$ & أشرك مراكز الخبرة التربوية عندوضيع الخطة الاستراتيجية للمدرسـة & it & 1 \\
\hline درجـة عالية & $1, r \leqslant 7$ & r,q1 & ارحب بمناقشـة انتقادات المجتمع حول على أداء المدرسة & 7 & r \\
\hline درجة عالية & $1, \varepsilon \wedge 1$ & r,ol & أوفر البيانات والمعلومات اللازمة لإتمام وتنفيذ عملية تحسين الأداء المدرسي & 0 & $r$ \\
\hline درجة عالية & $1,0 \leqslant 1$ & r,o. & اعمل على انسيابية قنوات المعلومات بين إدارة المدرسـة وإدارة التعليم & V & $\varepsilon$ \\
\hline 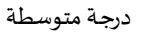 & $1, \varepsilon \uparrow \wedge$ & $r, \cdot v$ & اتابع الخطة العامة لوزارة التعليم & 11 & 0 \\
\hline درجة متوسطة & $1, \sum \sqrt{1}$ & $r, 7 \uparrow$ & احرص على تدريب وتأهيل العاملات خارجياً & 1. & 7 \\
\hline 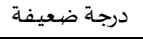 & $1, \varepsilon 19$ & $r, 0 \varepsilon$ & أفصح عن مؤشر الأداء للإدارة التنفيذية بشكل متكامل وفي الوقت الملائم & $\varepsilon$ & v \\
\hline 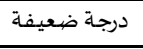 & $1, \Gamma \wedge \mathrm{V}$ & r,or & اقنع المسؤولين بجدوى الحوكمة كأداة لجودة الإنتاج & 1 & $\wedge$ \\
\hline درجة ضعيفة & $1, \varepsilon r$. & r,or & أشرك لجان تدقيق ومراجعة من خارج المدرسة لمراجعة أدائها المالي والإداري & r & 9 \\
\hline 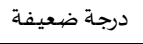 & $1, \mathrm{rV}$ & r,o. & اعتمد مبادئ الحوكمة كأحد عناصر تحسين الأداء المدرسي & r & 1. \\
\hline 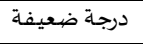 & $1, \varepsilon \mid \Gamma$ & $r, r v$ & يتم دفع مخصصيات المدرسة بناء على احتياجاتها الفعلية & $\wedge$ & 11 \\
\hline درجة ضعيفة & $1, r+$. & $r, 10$ & أقوم باستثمار مرافق المدرسـة للحصول على تمويل إضافي & 9 & ir \\
\hline درجة متوسطة & $1, r v$. & $r, 90$ & المتوسط الحسـابي & & \\
\hline
\end{tabular}

يتبين من الجدول السابق أن درجة تطبيق المتطلبات الخارجية من متطلبات الحوكمة الرشيدة في مدارس محافظة ينبع من وجهة نظر مديرات

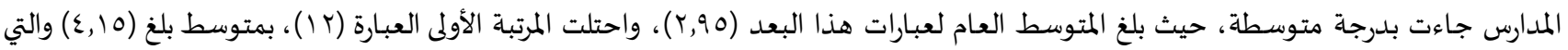

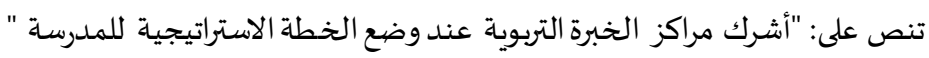

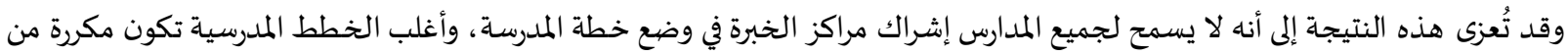

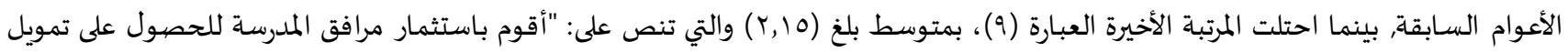


إضافي" وقد تُعزى هذه النتيجة إلى أن إدارة التعليم بمدينة ينبع لا تسمح للمدارس باستثمار مرافقها وهذا ينطبق على أغلب مدارس المملكة لأن الوزارة لا تسمح بذلك. • إجابة السؤال الر ابع وتفسيره ومناقشته: ينص السؤال الر ابع على: ما درجة تطبيق المتطلبات الخارجية من متطلبات الحوكمة الرشيدة في مدارس محافظة ينبع من وجهة نظر مديرات المدارس؟ ولالإجابة عن هذا السؤال تمَّ استخراج المتوسطات الحسابية والانحرافات المعيارية لجميع العبارات التي تمثل درجة تطبيق المتطلبات الخارجية

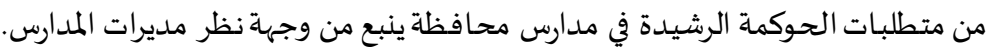

جدول(V): المتوسّطات الحسابية والانحر افات المعيارية لدرجة تطبيق المتطلبات الخارجية من متطلبات الحوكمة الرشيدة في مدارس محافظة ينبع من وجهة

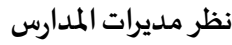

\begin{tabular}{|c|c|c|c|c|c|}
\hline 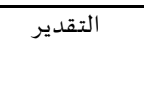 & الالمعياري & المتوسط الحسابي & ترتيب العبارة تنازلياً حسب المتوسطات & العبارة في & الترتيب \\
\hline درجة عالية & $1, r r \varepsilon$ & $r, \varepsilon \varepsilon$ & استغل المواردوالإمكانيات المتاحة في المدرسة بشكل ملائم & TV & 1 \\
\hline درجة متوسطة & 1, rri & r, ro & اتمتع بالقدرة على تحليل المشكلات المدرسية & ir & r \\
\hline 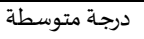 & $1,70 \mathrm{r}$ & $r, r_{1}$ & استخدم التكنولوجيا والتقنيات والبرامج الحديثة للحصول على المعلومات بوضوح & rt & $r$ \\
\hline درجة متوسطة & $1, \varepsilon \vee 9$ & $r, . \wedge$ & اعمل على وضوح واستقرار نظم وإجراءات العمل داخل المدرسة & 17 & $\varepsilon$ \\
\hline 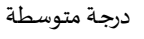 & $1,7 r \varepsilon$ & $r, . \cdot V$ & احقق مستوى من الثقة بين إدارة المدرسـة والعاملين فها & $r \varepsilon$ & $\circ$ \\
\hline درجة متوسطة & $1, \varepsilon 90$ & $r, .7$ & أقوم بتوفير قنوات اتصال فعالة مع أفراد المدرسة للحصول على معلومات عن سير & rq & 7 \\
\hline 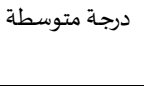 & $1, \varepsilon 77$ & $r, . \varepsilon$ & وفعالية أدائهن إعمل على الإداريات والمعلمات داخل المدرسة بدورات تدريبية لرفع كفاءتهن & 10 & v \\
\hline 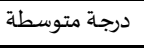 & $1,0 \leq 0$ & $r, . r$ & أوزع السلطة بين إدارة المدرسة والهيئة الإدارية في المدرسة & IV & $\wedge$ \\
\hline درجة متوسطة & 1,170 & $r, .1$ & امتلك القدرة على اتخاذ القرار الرشيد & $1 \varepsilon$ & 9 \\
\hline درجة متوسطة & $1, \varepsilon r q$ & r, VO & اشجع المعلمات في تقديم مقترحات خاصة بأد اهنن داخل المدرسة & 11 & 1. \\
\hline درجة متوسطة & 1,099 & $T, V \varepsilon$ & أوجد أسس عادلة في نظام الحوافز للعاملين في المدرسـة & 19 & 11 \\
\hline درجة متوسطة & 1,091 & T,VT & التزم بالشفافية والنزاهة في إدارتي للمدرسـة & r. & ir \\
\hline درجة متوسطة & 1,007 & r,Vi & أقوم بإعد اد هيكل تنظيمي ملائم لحوكمة المدارس & rl & ir \\
\hline درجة متوسطة & 1, ro. & $r, \mathrm{r}$ & أفصح عن معايير تعيين وترقية العاملين في المدرسة & ro & $1 \varepsilon$ \\
\hline 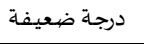 & $1, \varepsilon r q$ & r,07 & ربط التعليم داخل المدرسة بمتطلبات سوق العمل & rt & 10 \\
\hline درجة ضعيفة & $1, \varepsilon r \varepsilon$ & $r,\{7$ & لدي معرفة بمتطلبات الحوكمة وأهد افها في تحقيق جودة الأداء المدرسي & $r \wedge$ & 17 \\
\hline 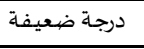 & $1, r \wedge 0$ & $r, \varepsilon r$ & احقق استقلالية المدرسة في جميع مجالات عملها & r & iv \\
\hline 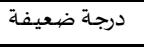 & $1, r \cdot V$ & $r, \varepsilon 1$ & احرص على وضيع بدائل في الخطة الاستراتيجية & $r$. & 11 \\
\hline 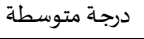 & $1, \varepsilon \varepsilon 0$ & r, VA & المتوسط الحسابي & & \\
\hline
\end{tabular}

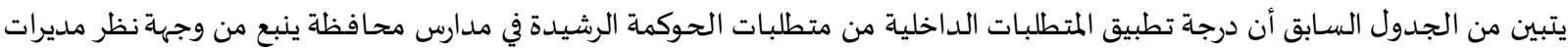

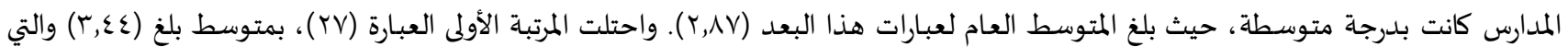

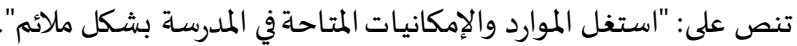

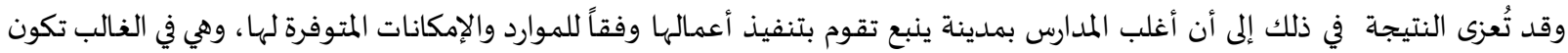

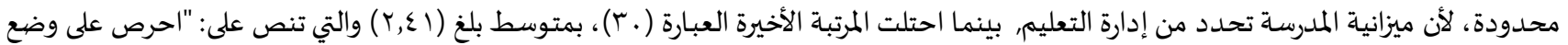

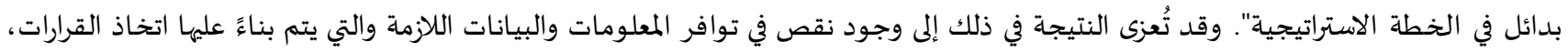

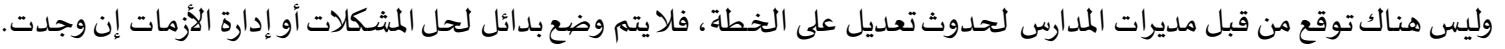

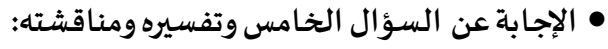

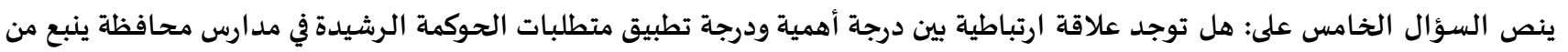

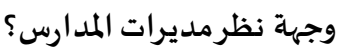
ولإجابة عن هذا السؤال، وللكشف عن العابر العلاقة الارتباطية بين درجة أهمية ودرجة تطبيق متطلبات الحوكمة الرشيدة في مدارس محافظة ينبع، تمَّ حساب معاملات الارتباط بيرسون والجدول (9) يوضح هذه العلاقة: 
جدول(^): معاملات الارتباط بين درجة أهمية ودرجة تطبيق متطلبات الحوكمة الرشيدة في مدارس محافظة ينبع من وجهة نظر مديرات المدارس

\begin{tabular}{|c|c|c|c|c|}
\hline \multicolumn{3}{|c|}{ درجة تطبيق متطلبات الجوكمة } & \multirow[t]{2}{*}{ الأبعاد } & \multirow[t]{2}{*}{ 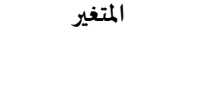 } \\
\hline الارتباط الكلي & | المتطلبات الداخلية & المتطلبات الخارجية & & \\
\hline., 11 & . Ir & •,. . Y & المتطلبات الخارجية & درجة أهمية متطلبات \\
\hline., 1 . &., .07 & $\cdot, \cdot \wedge \varepsilon$ & المتطلبات الداخلية & \\
\hline., .91 &.,.$v 1$ &., .09 & الارتباط الكلي & \\
\hline
\end{tabular}

يتبين من الجدول السـابق أنه لا توجد علاقة ارتباطية بين درجة أهمية ودرجة تطبيق متطلبات الحوكمة الرشيدة في مدارس محافظة ينبع،

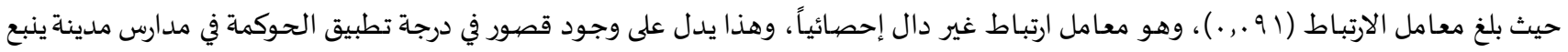
لأنه لم تتخذ قرارات تدعم عمليات تطبيق الحوكمة بشكل كامل، وإنما هناك بعض تطبيقات الحوكمة من خلال جزء من من الصلاحيات الممنوحة لمديرات

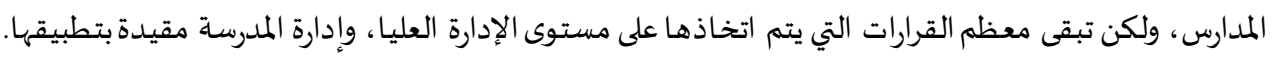

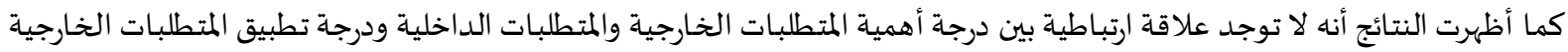
والمتطلبات الداخلية من متطلبات الحوكمة الرشيدة في مدارس محافظة ينبع، وهذا يدل على وجلى وجود فجوة بين درجة الأهمية ودرجة التطبيق، وهي فجوة كبيرة إذ ترى مديرات المدارس أهمية تحقيق متطلبات الحوكمةة، بينما الواقع الميداني لا يشير إلى وجود تطبيق لمتطلبات الحوكمة الرشيدة وهيدة.

\section{ملخص النتائج والتوصيات}

ملخص النتائج:

أن درجة أهمية المتطلبات الخارجية من متطلبات الحوكمة الرشيدة في مدارس محافظة ينبع من وجهة نظر مديرات المدارس كانت بدرجة عالية

أن درجة أهمية المتطلبات الداخلية من متطلبات الحوكمة الرشيدة في مدارس محافظة ينبع من وجهة نظر مديرات المدارس كانت بدرجة عالية

أن درجة تطبيق المتطلبات الخارجية من متطلبات الحوكمة الرشيدة في مدارس محافظة ينبع من وجهة نظر مديرات المدارس كانت بدرجة

متوسطة.

أن درجة تطبيق المتطلبات الداخلية من متطلبات الحوكمة الرشيدة في مدارس محافظة ينبع من وجهة نظر مديرات المدارس كانت بدرجة متوسطة.

أنه لا توجد علاقة ارتباطية بين درجة أهمية ودرجة تطبيق متطلبات الحوكمة الرشيدة في مدارس محافظة ينبع من وجهة نظر مديرات المدارس.

التوصيات:

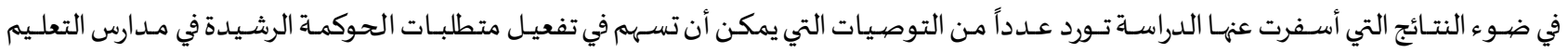

العام للبنات بمحافظة ينبع من وجهة نظر مديرات المدارس، وهي كما يلي:

العمل على التذسيق بين إدارة التربية والتعليم والإدارة المدرسية للبنات بمدينة ينبع فيما يتعلق بالقرارات المتعلقة بتطبيق مدخل الحوكمة

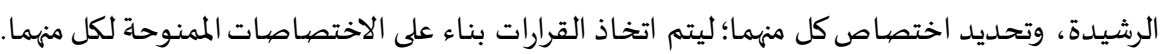

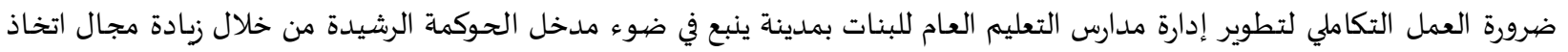
القرارات المتعلقة بمجالات إدارة المدارس لتطوير الأداء وتسهيل مهمة المدرسة في اتخاذ القرارات الفعالة التي تؤدي إلى تحسين جوانب العمل داخل المدرسة. ضرورة ترك الحرية الكاملة لإدارة مدارس التعليم العام في تحديد مصادر تمويل المدرسة وصرفها في الجوانب التي تقدرها المدرسة، نظراً لأن إدارة المدرسة هي الجهاة الوحيدة القادرة على تحديد متطلبات المدرسة وتوفيرها بالسرعة الممكنة دون تعقيد الإجراءات المالية المتعلقة بذلك. التعاون مع أعضاء هيئة التدرد في الكليات والجامعات السعودية، وخاصة في أقسام الإدارة والتخطيط التربوي للتوسع في الدورات التدربيية المقدمة لمديرات مدارس التعليم العام للبنات بمدينة ينبع حول مدخل الحوكمة الرشيدة لتطوير الأداء المدرسي والاستفادة من خبرات وإبداعات

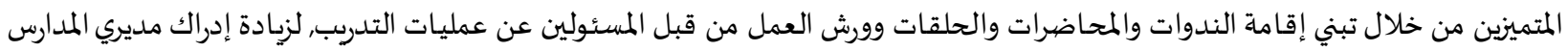

$$
\text { نحوها من حيث المعرفة والممارساة. }
$$




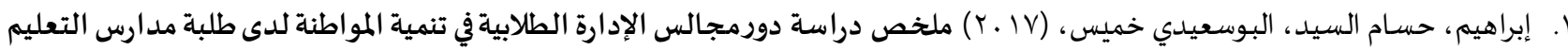

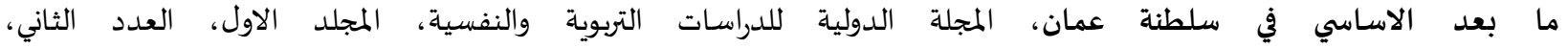
https://doi.org/10.12816/0040847

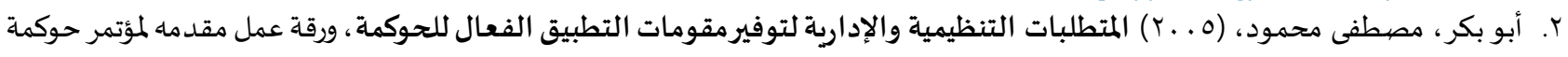

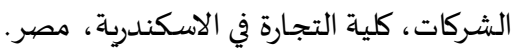

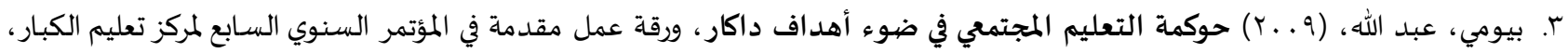

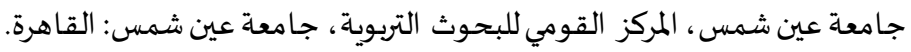

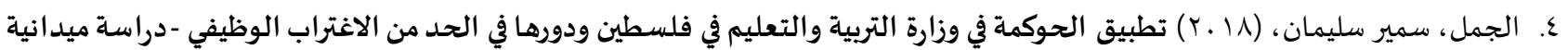

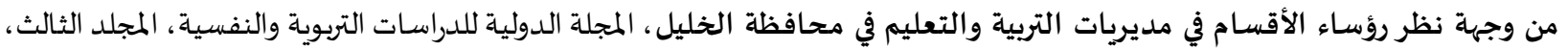

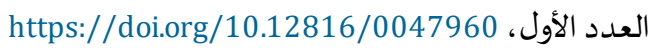

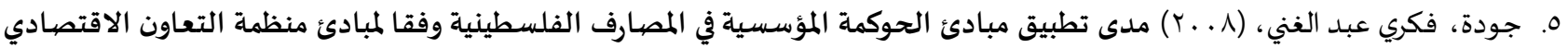

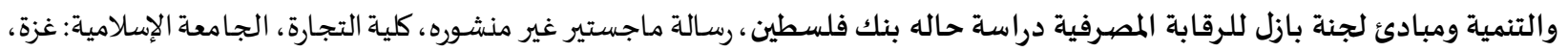
فلسطين.

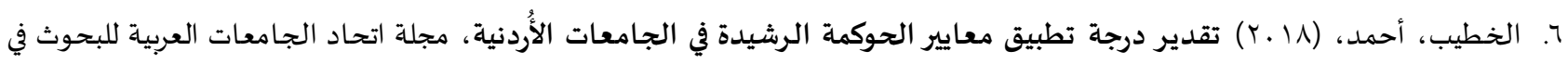

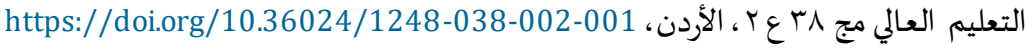

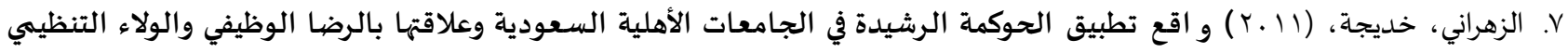

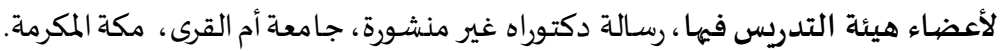

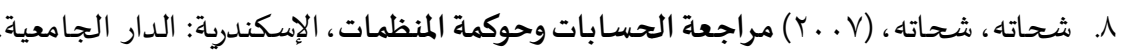

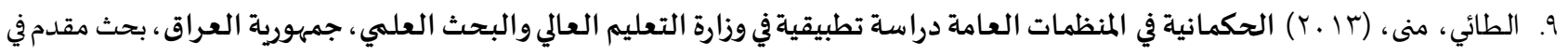

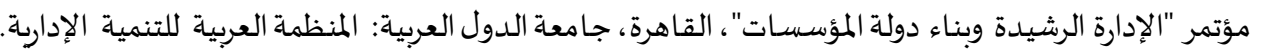

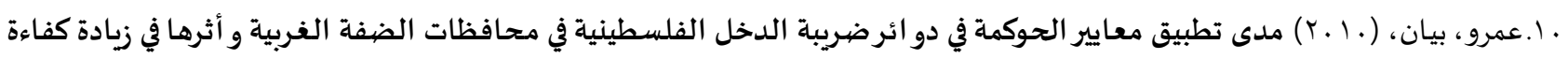

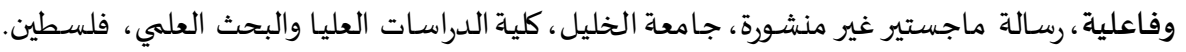

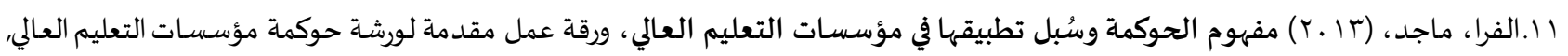

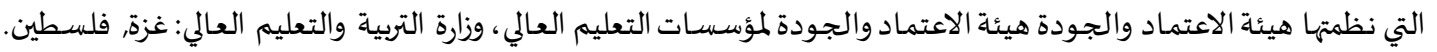

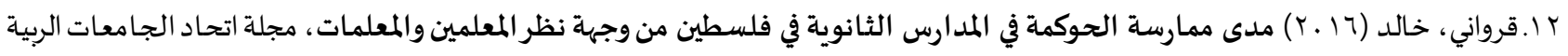

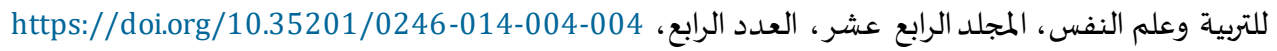

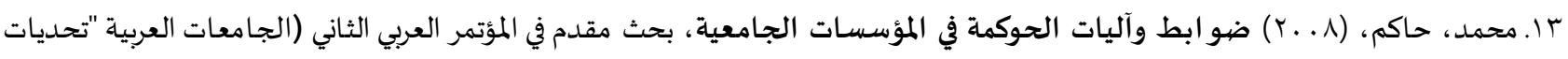
وطموح). مراكش ، المملكة المغربية.

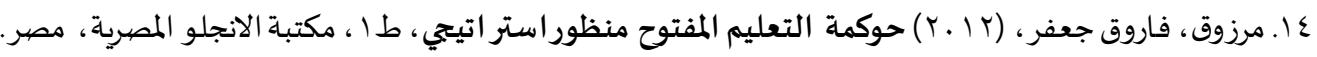

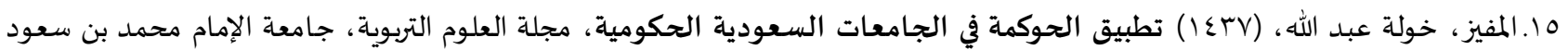

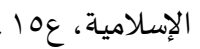

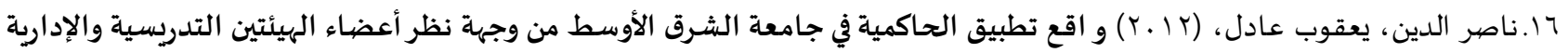

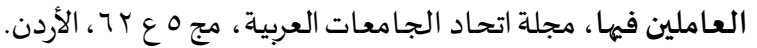

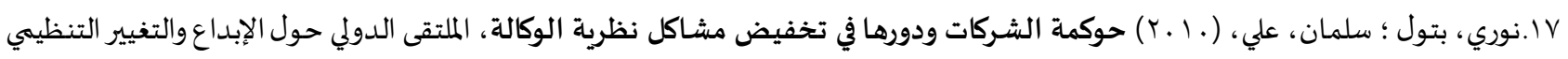
في المنظمات الحديثة، الجامعة المستنصرية، العراق. 11. يوسف، أمير ، (. (Y) حوكمة الشركات، الإسكندرية: دار المطبوعات الجامعية.

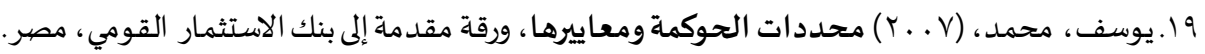


[1] Bradley. Letitia T. , Effective Governance: The Impact of the Masters in Governance Training on School Boards in California, ProQuest LLC, Ed .D. Dissertation, University of Southern California, (2015)

[2] Higham. Rob, Who Owns Our Schools? an Analysis of the Governance of Free Schools in England, Educational Management Administration \& Leadership, 42(3)(2014), 404-422, https://doi.org/10.1177/1741143214522203

[3] Jennifer. Jellison \& Diem, Sarah, regional Governance in Education: A Case Study of the Metro Area Learning Community in Omaha, Nebraska, Peabody Journal of Education, 90(1)(2015), 156-177, https://doi.org/10.1080/0161956x.2015.988546 


\title{
The Requirements of Good Governance in the General Education Schools for Girls in Yanbu from the Point of View of School Principals
}

\author{
Majdaleen Mahmoud Alqaoud \\ Professor of Educational Administration Assistant, at the University of Taibahu previously \\ Magiq100@gmail.com
}

Entesar Faraj Hassan Baket

Directorate of General Education in Yanbu entbkt13@gmail.com

\begin{abstract}
The study aimed to identify the degree of availability of good governance requirements (internal and external) in the schools of Yanbu, and determine the degree of importance to improve the performance of public education for girls schools stems province. Was used descriptive method Correlative, and the final study sample consisted of (68), director of school principals in Yanbu for the academic year 39/1440H. the questionnaire was used as a tool for collecting data and information

The study concluded that a set of results was the most important: The degree of importance of the requirements of internal and external requirements of good governance in the schools of the province stems from the standpoint of the requirements of school principals was very high degree.

The degree of application of the requirements of internal and external requirements of good governance in the schools of the province stems from the standpoint of the requirements of school principals were moderately.

That there is no correlation between the degree of importance and degree of implementation of good governance in the schools of the province stems from the standpoint of the requirements of school principals

In light of the findings of the study made a number of recommendations including:

Work on coordination between the Department of Education and school administration for girls in Yanbu in relation to decisions concerning the application of the entrance to good governance, and to determine the jurisdiction of each of them; to be making decisions based on the terms of reference given to each.

the need for complementary work to develop public education for girls in schools management stems in light of the entrance to good governance by increasing the area of decision-making in the areas of school management for the development of performance and to facilitate the task of the school in effective decision making
\end{abstract}

Keywords: Good governance; Governance requirements; General Education Schools for Girls in Yanbu.

\section{References:}

[1] 'mrw. Byạn, Mda Tṭbyq M'ạyr Alhwkmh Fy Dwạ̉r Drybh Aldkhl Alflstynyh Fy Mhạatạt Aldfh Alghrbyh

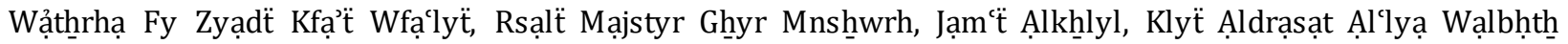
Ạl'lmy, Flsțn, (2010)

[2] Abrạhym. Hsạm Ạlsyd \& Ạlbws'ydy Khmys, Mlkḥs Drạsë Dwr Mjạls Ạladạarh Ạlṭlạbyh Fy Tnmyë Ạlmwạtnh Lda Ṭ̉lb̈̈ Mdạrs Ạlt'lym Mạ B`d Ạlạsạsy Fy Slṭ̂̈ ‘mạn, Ạlmjlh Ạldwlyh Lldrạsạt Ạltrbwyh Wạlnfsyh, Ạlmjld Ạlạwl, Ạl'dd Althạany, (2017) https://doi.org/10.12816/0040847

[3] Ạ̉bw Bkr. Mșța Mḥmwd, Ạlmtțlbạt Ạltnzymyh WạląDạryh Ltwfyr Mqwmạt Ạltțbyq Ạlfạl Llḥwkmh, Wrqü 'ml Mqdmh Lmw̉tmr Ḥwkmë Ạlshrkạt, Klÿ̈ Ạltjạrh Fy Ạlạskndryh, Mṣr, (2005) 
[4] Bradley. Letitia T. , Effective Governance: The Impact of the Masters in Governance Training on School Boards in California, ProQuest LLC, Ed .D. Dissertation, University of Southern California, (2015)

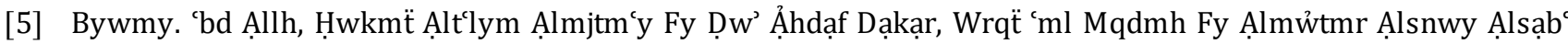

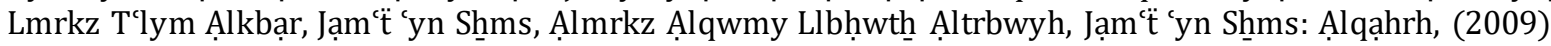

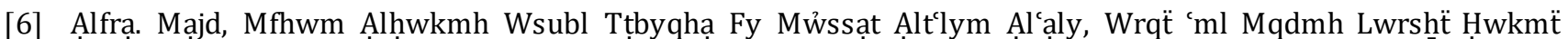
Mw̉ssạt Alttlym Ạl'ạly, Ạlty Nẓmthạ Hyỷë Ạlạ̣tmạd Wạljwdh Hyỷêt Ạlạ̣tmạd Wạljwdh Lmw̉ssạt Alttlym Ạl'ạly, Wzạrẗ Ạltrbyh Wạlt'lym Ạl'ạly: Gḥza, Flsțnn, (2013)

[7] Higham. Rob, Who Owns Our Schools? an Analysis of the Governance of Free Schools in England, Educational Management Administration \& Leadership, 42(3)(2014), 404-422, https://doi.org/10.1177/1741143214522203

[8] Jennifer. Jellison \& Diem, Sarah, regional Governance in Education: A Case Study of the Metro Area Learning Community in Omaha, Nebraska, Peabody Journal of Education, 90(1)(2015), 156-177, https://doi.org/10.1080/0161956x.2015.988546

[9] Ạljml. Smyr Slymạn, Tṭbyq Ạlḥwkmü Fy Wzạrẗ Ạltrbyh Wạltlym Fy Flsțn Wdwrhạ Fy Ạlḥd Mn Ạlạgh̄trạb Ạlwzyfy - Drạsh Mydạnyh Mn Wjḧ̈ Nẓr Rw̉sạ’ Ạlạ̉qsạm Fy Mdyryạt Ạltrbyh Wạltlym Fy Mḥạfặ Ạlkhlyl, Ạlmjlh Ạldwlyh Lldrạsạt Ạltrbwyh Wạlnfsyh, Ạlmjld Ạlthạalth̄, Ạl'dd Ạlạ̉wl, (2018), https://doi.org/10.12816/0047960

[10] Jwdh, Fkry 'bd Ạlghnyy, Mda Tṭbyq Mbạda Ạlḥwkmh Ạlmw̉ssyh Fy Ạlmṣạrf Ạlflsțnyh Wfqạ Lmbạdỷ Mnẓmë Ạlt‘ạwn Alạqtṣạdy Wạltnmyh Wmbạdỷ Ljn̈̈ Bạzl Llrqạbh Ạlmṣrfyh Drạsẗ Hạlh Bnk Flsțnn, Rsạlẗ Mạjstyr Ghyr Mnshwwrh, Klÿ̈ Ạltjạrh, Ạljạm`h Ạlạslạmyh: Ghzza, Flsțyn, (2008)

[11] Ạlkhtyb. Ạ̉hmd, Tqdyr Drjë Tṭbyq M'ạyyr Ạlḥwkmh Ạlrshydh Fy Ạljạm ‘ạt Ạlạurdnyh, Mjlï Ạthạd Ạljạm‘ạt Ạl'rbyh Llbḥwth Fy Ạlt'lym Ạl ‘ạly Mj 38 ` 2, Ạlạ̉rdn, (2018), https://doi.org/10.36024/1248-038-002-001

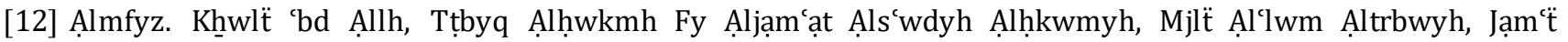
Alạmạm Mḥmd Bn S'wd Ạlạslạmyh, '15 , (1437)

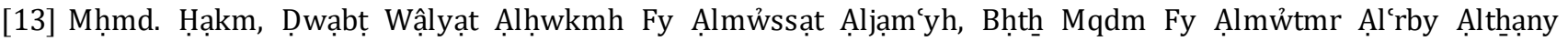

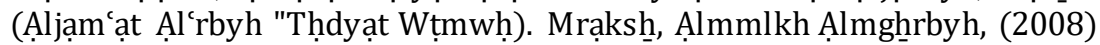

[14] Mrzwq. Fạrwq J’fr, Ḥwkmë Ạlt'lym Ạlmftwḥ Mnẓwr Ạstrạtyjy, Ṭ1, Mktbë Ạlạnjlw Ạlmșryh, Mṣr, (2012)

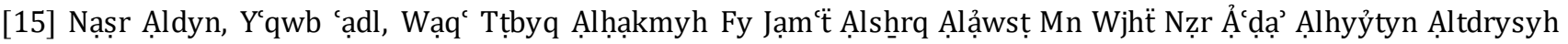
Wạlạjạryh Ạl'ạmlyn Fyhạ, Mjlë Ạthạd Ạljạmª̣t Ạl'rbyh, Mj 5 ` 62, Ạlạ̉rdn, (2012)

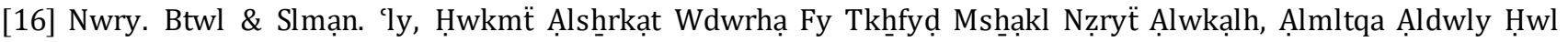

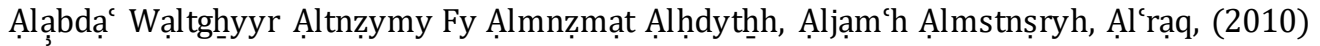

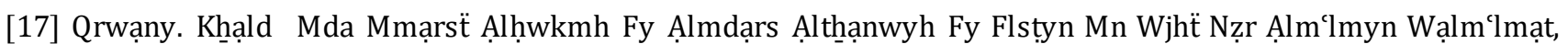
Mjlï Athạd Ạljạm‘ạt Ạlrbyh Lltrbyh W'lm Ạlnfs, Ạlmjld Ạlrạb' 'shnr, Ạl'dd Ạlrạb', (2016) https://doi.org/10.35201/0246-014-004-004

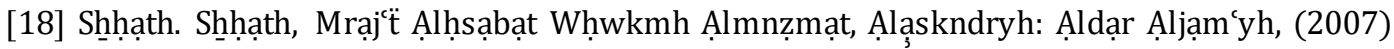

[19] Ạlțạyy. Mna, Ạlḥkmạnyh Fy Ạlmnẓmạt Ạl'ạmh Drạsh Tṭbyqyh Fy Wzạrë Ạlt'lym Ạl'ạly Wạlbḥth Ạl'lmy,

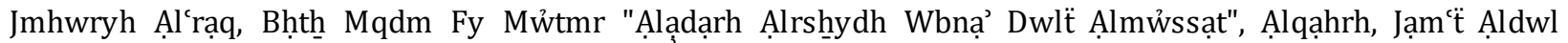
All'rbyh: Ạlmnẓmh Ạl'róbyh Lltnmyh Ạlạiạryh, (2013)

[20] Ywsf. Mḥmd, Mḥddạt Ạlḥwkmh Wm`ạyyrhạ, Wrqü Mqdmh A̦La Bnk Ạlạsttḥmạr Ạlqwmy, Mṣr, (2007)

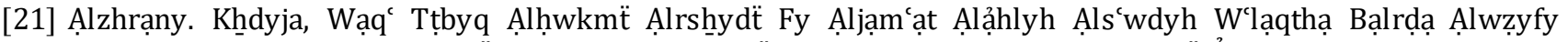

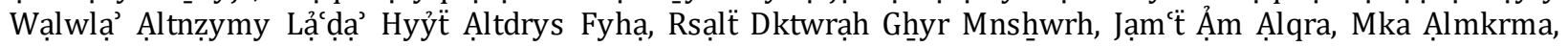
(2011) 